\title{
PELATIHAN PEMBUATAN ALAT PERAGA MESIN STIRLING UNTUK GURU FISIKA SMA
}

\author{
Oleh: \\ Meta Yantidewi ${ }^{1}$, Tjipto Prastowo ${ }^{2}$, Titin Sunarti ${ }^{3}$, Utama Alan Deta ${ }^{4}$ \\ 1,2,3,4Jurusan Fisika FMIPA Universitas Negeri Surabaya \\ ${ }^{1}$ metayantidewi@unesa.ac.id
}

\begin{abstract}
Abstrak
Fisika merupakan salah satu cabang IPA yang mendasari perkembangan teknologi maju dan konsep hidup harmonis dengan alam. Pada pembelajaran fisika, pemahaman konsep dengan pengalaman belajar langsung dapat dilakukan melalui kegiatan eksperimen atau praktikum dengan memanfaatkan alat peraga praktikum di Laboratorium Fisika sekolah maupun demonstrasi di depan kelas. Pengembangan alat peraga Mesin Stirling dan penyusunan LKS terkait bertujuan untuk meningkatkan kompetensi pedagogi dan profesi guru-guru Fisika SMA yang tergabung dalam MGMP Fisika SMA Dinas Pendidikan Kabupaten Bojonegoro, agar terampil membuat dan menggunakan media pembelajaran Fisika SMA yang sederhana serta dapat menunjang pembelajaran Fisika SMA. Kegiatan pelatihan oleh Tim PKM 2017 Jurusan Fisika FMIPA Unesa ini dilaksanakan dalam tiga tahapan, yakni: perancangan, pembuatan alat peraga praktikum termofisika, dan evaluasi menyeluruh. Kegiatan ini diharapkan mampu meningkatkan kompetensi pedagogi dan profesi guru-guru Fisika SMA Kabupaten Bojonegoro, terutama dalam pembuatan media dan alat peraga praktikum fisika sekaligus sebagai bentuk pendampingan pembelajaran Fisika berbasis pendekatan saintifik. Kegiatan workshop direncanakan akan diikuti oleh beberapa guru Fisika SMA Kabupaten Bojonegoro. Waktu penyelenggaraan kegiatan workshop adalah pada hari Sabtu 21 Oktober 2017. Kinerja peserta pelatihan kali ini rata-rata sudah sangat baik. Adapun respon para peserta terhadap kegiatan ini juga sangat baik. Terbukti dari lembar uji kinerja dan respon peserta pelatihan yang menunjukkan bahwa $70 \%$ peserta memiliki kinerja yang sangat baik serta lebih dari $70 \%$ peserta yang menyatakan bahwa acara ini sangat baik dalam mendukung pemahaman siswa terhadap materi termofisika, utamanya Mesin Stirling.
\end{abstract}

Kata Kunci: alat peraga, Mesin Stirling, kegiatan pelatihan

\begin{abstract}
Physics is a part of sciences that underlies the development of advanced technology and the concept of living in harmony with nature. In physics learning, conceptual understanding with direct learning experience might be able to carry out through experimental or practicum activities by utilizing practicum tools in the Physics Laboratory of school and also by holding out some demonstrations during class. The development of thermophysical practicum tools and the arrangement of related student workbook (LKS) are mainly purposed to improve the pedagogical and profession competence of high school physics teachers who are members of MGMP Fisika SMA Dinas Pendidikan Kabupaten Bojonegoro, to be accustomed and skillful to make and use of high school physics learning which is simple and can support high school physics learning. The training activities by the 2017 PKM Team are carried out in three stages: designing, manufacturing of thermophysical practicum tools, and comprehensive evaluations. This activity is expected to increase the pedagogical and profession competence high school physics teachers of Kabupaten Bojonegoro, especially in the manufacture of media and practicum visual This activity is expected to increase the competence of pedagogy and profession of high school physics teachers of Bojonegoro Regency, especially in the manufacture of media and visual practicum visuals as well as a form of teaching a physics-based approach to a scientific approach. Workshop activities are planned to be followed by several high school physics teachers of Bojonegoro Regency. The time of the workshop is on Saturday 21st of October 2017. The average performance of the trainees this time has been very good. The participants' responses to this activity are also very good. Evident from the performance test sheet and training participants 'responses indicating that $70 \%$ of the participants had excellent performance and more than $70 \%$ of participants stated that the event was excellent in supporting students' understanding of the thermophysical material, especially Stirling Machine.
\end{abstract}

Keywords: your keyword should not exceed five keywords

\section{PENDAHULUAN}

IImu Pengetahuan Alam (IPA) merupakan kumpulan pengetahuan yang sistematis dan logis yang bertujuan untuk mempelajari fenomena alam. Fisika merupakan salah satu 
cabang IPA yang mendasari perkembangan teknologi maju dan konsep hidup harmonis dengan alam (Sudarmadi, 2012).

Pada tingkat SMA dan yang sederajat, fisika dipandang sebagai perlu untuk diajarkan sebagai mata pelajaran tersendiri. Hal ini didasari oleh beberapa poin pertimbangan antara lain: (1) agar siswa memiliki bekal dasar dalam mengembangkan kemampuan berpikir logis; (2) agar siswa siap memasuki jenjang pendidikan yang lebih tinggi serta mampu mengembangkan IPTEK bila dibekali sejumlah pengetahuan, pemahaman, dan kemampuan yang cukup (Sudarmadi, 2012).

Pada pembelajaran fisika, pemahaman konsep dengan pengalaman belajar langsung dapat dilakukan melalui kegiatan eksperimen atau praktikum (Rahayu dkk, 2016). Kegiatan praktikum ini tentunya memerlukan sarana dan prasarana yang memadai seperti laboratorium dan alat peraga praktikum yang sesuai. Penggunaan alat peraga praktikum membantu memudahkan guru dalam menjelaskan suatu konsep kepada siswa, selain itu juga memudahkan siswa dalam memahami suatu konsep secara tidak langsung.

Selama 4 tahun berturut-turut Tim PKM Jurusan Fisika telah berhasil menyelenggarakan kegiatan berupa workshop pembuatan alat praktikum IPA Fisika dan penyusunan LKS bagi guru-guru IPA SMP (Rahmawati dkk, 2013; Anggaryani dkk, 2013; Rahmawati dkk, 2014; Prastowo dkk, 2015; Prastowo dkk, 2016). Kegiatan ini mendapat respon yang sangat baik dari para guru yang mengikuti pelatihan.

Dengan keberhasilan tersebut, maka Tim PKM Jurusan Fisika pada tahun 2017 telah menrencanakan dan melaksanakan kegiatan ini PKM dengan tema pembuatan media pembelajaran dan alat peraga Mesin Stirling bagi guru-guru fisika SMA Kabupaten Bojonegoro. Pertimbangan bekerjasama dengan MGMP Fisika SMA Dinas Pendidikan Kabupaten Bojonegoro adalah selain pemerataan peningkatan kualitas guru dalam mengajarkan materi fisika SMA juga untuk meningkatkan kualitas pengajaran fisika melalui kegiatan workshop pembuatan media dan alat peraga Mesin Stirling. Alat peraga praktikum yang dilatihkan ini berasal dari barang bekas atau bahan-bahan yang mudah didapatkan, namun cara kerjanya tetap berdasarkan prinsip-prinsip sains.

Sebagaimana telah diuraikan di atas, berikut ini merupakan poin-poin yang menjadi pokok permasalahan Mitra PKM 2017: 1)
Belum tersedia perangkat pembelajaran terkait alat peraga praktikum fisika SMA yang relevan dengan tema termofisika (LKS dan petunjuk praktikum untuk guru) di Kabupaten Bojonegoro; 2) belum meratanya kualitas guru Fisika SMA di Kabupaten Bojonegoro dalam bidang pengajaran fisika yang berbasis kegiatan praktikum.

\section{METODE}

Berikut ini metode pelaksanaan kegiatan workshop pembuatan alat peraga Mesin Stirling untuk guru-guru Fisika SMA Kabupaten Bojonegoro oleh Tim PKM Jurusan Fisika FMIPA Unesa yang dilaksanakan dalam tiga tahap, yaitu:

a. Tahap pertama adalah mengembangkan alat peraga Mesin Stirling untuk guru-guru Fisika SMA. Selanjutnya dilakukan pembuatan prototype alat peraga Mesin Stirling dan uicoba terbatas terlebih dahulu. Hasil ujicoba terbatas ini nantinya digunakan untuk penyusunan LKS dan petunjuk penggunaan alat peraga Mesin Stirling untuk guru (teacher's guide) yang berorientasi pada pendekatan saintifik;

b. Tahap kedua yang meliputi:

1) Brainstorming tentang Mesin Stirling

2) Pelatihan pembuatan kit alat peraga praktikum fisika Mesin Stirling

3) Latihan menyusun LKS yang sesuai dengan alat peraga Mesin Stirling hasil workshop

4) Ujicoba terbatas (simulasi) alat peraga Mesin Stirling hasil workshop yang telah dibuat oleh peserta pada kelas tersebut secara berkelompok

c. Tahap ketiga adalah evaluasi menyeluruh terkait dengan manfaat pembuatan alat peraga Mesin Stirling dengan pendekatan saintifik berbasis barang bekas atau bahan sederhana untuk pengajaran fisika SMA yang lebih baik. Sesi diskusi pada akhir kegiatan workshop digunakan untuk membahas kendala-kendala teknis yang dijumpai di sekolah masing-masing.

\section{HASIL DAN PEMBAHASAN}

Pelatihan pembuatan alat peraga Mesin Stirling ini dilaksanakan di SMA PGRI Sumberrejo Kabupaten Bojonegoro dengan 
peserta adalah para guru Fisika SMA di Kabupaten Bojonegoro sebanyak 20 orang. Alat peraga yang dilatihkan pembuatannya adalah alat peraga praktikum termofisika berupa kit prototipe Mesin Stirling. Kit prototype Mesin Stirling ini terbuat dari bahan-bahan yang relatif mudah diperoleh. Adapun bahanbahan yang digunakan untuk membuat prototipe Mesin Stirling ini antara lain: tabung reaksi berdiameter $1 \mathrm{~cm}$ dan panjang $15 \mathrm{~cm}$, kayu, selang plastik, kelereng kecil berdiameter 0,8 cm, kawat tembaga, spuit plastik, pembakar spirtus, sumbat karet, dan minyak pelumas. Foto-foto berikut menunjukkan alat peraga Mesin Stirling yang telah dibuat.

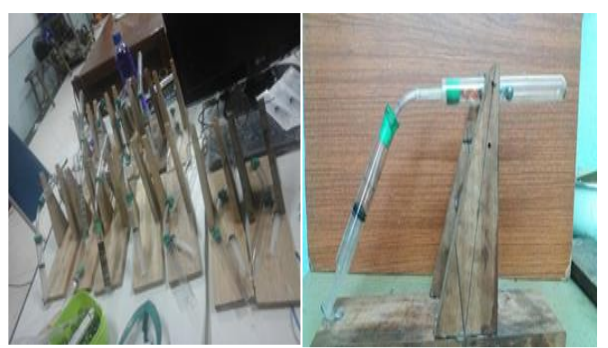

Gambar 1. Alat Peraga Mesin Stirling

Pembuatan kit Mesin Stirling ini juga melibatkan mahasiswa Jurusan Fisika.

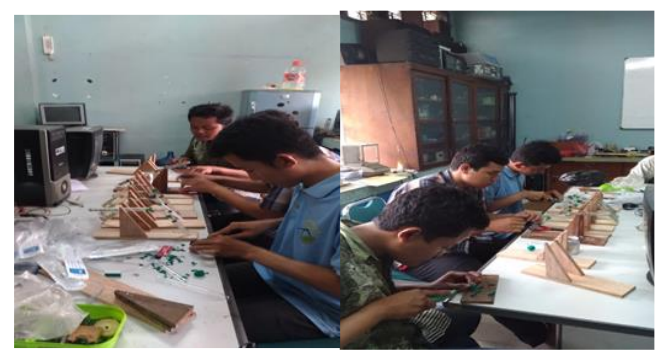

Gambar 2. Pembuatan Kit Mesin Stirling

Dalam kegiatan pelatihan PKM 2017 ini juga dilakukan penilaian peserta sebagai tolak ukur tingkat pemahaman dan antusias peserta. Hasil penilaian kinerja keterampilan proses sains meliputi: membaca petunjuk (A1), melaksanakan percobaan (A2), mengamati fenomena fisis (A3), mengumpulkan data (A4), menyimpulkan hasil percobaan (A6), menalar temuan percobaan, (A5), dan mengkomunikasikan informasi ilmiah (A7). Produk sains yang dinilai berupa alat peraga Mesin Stirling (B1) dan menyusun LKS (B2). Hasil penilaian Sembilan indicator disajikan pada Gambar 3.

Berdasarkan Gambar 3, keterampilan proses sains peserta tergolong sangat baik terutama dalam kegiatan membaca petunjuk
(A1), melaksanakan percobaan (A2), mengamati fenomena fisis (A3), mengumpulkan data (A4), dan menyimpulkan hasil percobaan (A6) dengan rata-rata berturut-turut 4,0; 3,7; 3,5; 3,6; dan 3,9. Sedangkan untuk keterampilan proses sains dalam menalar temuan percobaan (A5) dan mengkomunikasikan informasi ilmiah (A7) masih tergolong baik dengan rata-rata masingmasing 3,5.

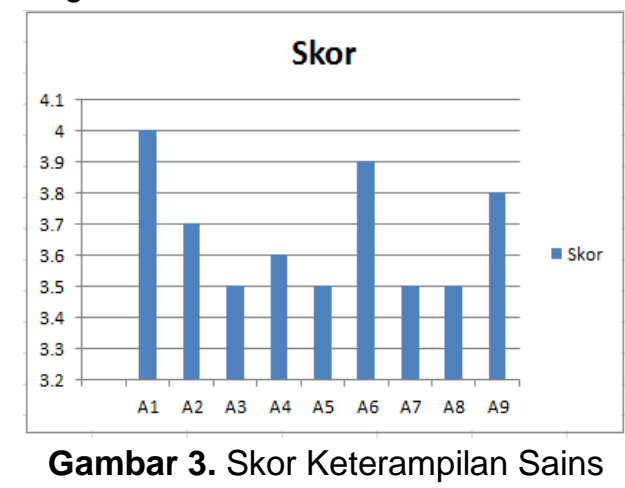

Produk sains yang dinilai berupa alat peraga Mesin Stirling (B1) dan LKS terkait alat peraga Mesin Stirling (B2). Berdasarkan penilaian kedua indicator tersebut, rata-rata keduanya menunjukkan angka 3,5 dan 3,8. Rata-rata tersebut menunjukkan bahwa produk sains yang dihasilkan masuk dalam kategori sangat baik. Secara keseluruhan, peserta yang mendapat predikat baik ada 6 orang dari 20 peserta atau sama dengan $30 \%$. Sisanya $70 \%$ dari total peserta mendapat predikat sangat baik dalam pelatihan ini. Gambar 4 menunjukkan persentase peserta pelatihan yang mendapat predikat baik dan sangat baik.

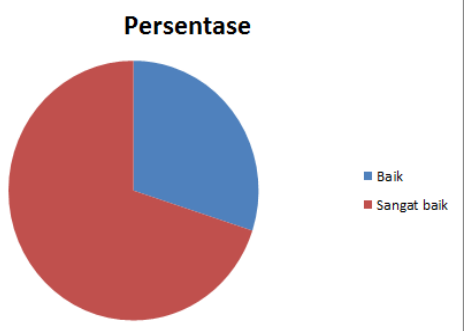

Gambar 4. Persentase Predikat Peserta

Setelah menyelesaikan seluruh tahap mencoba kit Mesin Stirling dan mendiskusikan hasil pengamatan, maka peserta pelatihan mengisi angket yang berisi respon peserta pelatihan terhadap 4 aspek yang terdapat dalam kegiatan pelatihan. Empat aspek tersebut antara lain: kesesuaian dengan tujuan pembelajaran, kesesuaian dengan materi pembelajaran, kesesuaian dengan karakteristik siswa, dan karakteristik kit Mesin 
Stirling dan LKS terkait. Data respon peserta pelatihan disajikan pada Tabel 1.

Tabel 1. Respon Peserta Pelatihan Pembuatan Alat Peraga Mesin Stirling

\begin{tabular}{llc}
\hline \multicolumn{1}{c}{ Aspek yang dinilai } & \multicolumn{2}{c}{ Predikat (\%) } \\
\cline { 2 - 3 } & B & SB \\
\hline Kesesuaian dengan tujuan pembelajaran & 30 & 70 \\
\hline $\begin{array}{l}\text { Mengembangkan aspek kogitif, afektif, dan psikomotor } \\
\text { (atau KI yang setara dalam K13) }\end{array}$ & 20 & 80 \\
\hline Meningkatkan aktivitas dan partisipasi siswa & 10 & 90 \\
\hline Memberikan peran pembimbing pada guru & 50 & 50 \\
\hline Kesesuaian dengan materi pembelajaran & 25 & 75 \\
\hline Kedalaman dan kecakupan informasi & 35 & 65 \\
\hline Mendukung pemahaman konsep fisika & 30 & 70 \\
\hline Memberikan contoh konkret & 5 & \\
\hline Memberikan pengetahuan baru & 45 & 55 \\
\hline Kesesuaian dengan karakteristik siswa & 20 & 80 \\
\hline Menarik minat dan meningkatkan motivasi belajar & 30 & \\
\hline Sesuai perkembangan pengetahuan dan psikologi & 70 \\
\hline Memungkinkan siswa belajar mandiri terbimbing & 30 & 70 \\
\hline Karakteristik alat peraga Mesin Stirling dan LKS terkait & 30 & 70 \\
\hline Relevasi antara alat peraga dan LKS terkait & 15 & 85 \\
\hline Mamp memenuhi tujuan pembelajaran & 10 & 90 \\
\hline Menarik secara tampilan & & \\
\hline Mudah dan murah dibuat & & \\
\hline Mendukung kinerja guru dalam PBM & & \\
\hline
\end{tabular}

Keterangan: $\mathrm{SB}=$ sangat baik

$$
\text { B = baik }
$$

\section{SIMPULAN DAN SARAN}

\section{Simpulan}

Berdasarkan isian lembar angket respon peserta pelatihan diperoleh temuan bahwa rata-rata peserta menyatakan bahwa kegiatan pelatihan ini sudah sangat baik terutama dalam aspek menarik minat dan meningkatkan motivasi belajar siswa pada materi termofisika utamanya Mesin Stirling, sedangkan berdasarkan isian lembar penilaian kinerja peserta dalam kegiatan ini sudah sangat baik.

\section{Saran}

Harapan dan saran Tim PKM sebagai pelaksana kegiatan pelatihan PKM adalah kegiatan ini mampu berlanjut dan bermanfaat bagi para guru Fisika SMA di Kabupaten Bojonegoro.

\section{DAFTAR PUSTAKA}

Prastowo, Tjipto dkk. 2016. Pelatihan Pembuatan Alat Peraga Praktikum Fisika dengan Pendekatan Saintifik untuk Guru
IPA SMP di Kabupaten Bojonegoro. Laporan Akhir PKM tidak dipublikasikan. Surabaya:Unesa.

Sari, Diana Novia dkk. 2014. Pengembangan Alat Praktikum Sederhana dan Modul Penuntun Praktikum untuk Materi Listrik Dinamis pada Pelajaran Fisika Kelas $X$ SMA. Edusaintika Jurnal Pendidikan MIPA.v.I (1), p.18-20

Sudarmadi. 12 April 2012. Meningkatkan Kemampuan Guru-Guru Fisika SMA/SMK Binaan dalam membuat Alat Praktikum Fisika Sederhana Melalui Pendampingan di Kabupaten Kulonprogo. Prosiding Pertemuan IImiah XXVI HFI Jateng dan DIY. p.196-202. Purworejo.

Rahayu, Arum dkk. 2016. Pengembangan Set Praktikum Pembiasan Cahaya untuk Pembelajaran Fisika di SMA. Prosiding Seminar Nasional Fisika (E-Journal) SNF 2016. V (Oktober 2016). p.1-6. http://snf-uni.ac.id/kumpulanprosiding/snf2016 (diunduh tanggal 15 April 2017) 